\title{
Integration of activity-based budgeting and activity-based management
}

\author{
Tandung Huynh ${ }^{1}$, Guangming Gong ${ }^{2}$, Huyhanh Huynh ${ }^{3}$ \\ ${ }^{1}$ Business School, Hunan University, Hunan, China, Faculty of Accounting and Auditing in Industrial University, Hochiminh City, Vietnam \\ ${ }^{2}$ Business School, Hunan University, Hunan, China \\ ${ }^{3}$ Faculty of Accounting and Auditing in Industrial University, Hochiminh City, Vietnam
}

Email address:

huynhtandung_hnu@yahoo.com(T. Huynh)

\section{To cite this article:}

Tandung Huynh, Guangming Gong, Huyhanh Huynh. Integration of Activity-Based Budgeting and Activity-Based Management. International Journal of Economics, Finance and Management Sciences. Vol. 1, No. 4, 2013, pp. 181-187.

doi: $10.11648 /$ j.ijefm.20130104.11

\begin{abstract}
Activity-Based Costing (ABC)/Activity-Based Management (ABM) was developed in the mid 1980s by Kaplan and it has been applied very popular in developed countries with obvious advantages. Although ABC system has more advantages than traditional systems, but in today's competitive economic environment it has not met fulfilled provision of sufficient information for decision-making. The ABC/ABM system alone, however, lacks the ability to support information for managerial decisions. We can summary the limitations of single ABC in today's business environment as follow: (1) ABC was originally developed because traditional costing appeared to be providing misleading product costs. Only single $\mathrm{ABC}$ using, it just provides an alternative way to trace costs to products, (2) lack of planning and control cost. ABC/ABM discusses a product has already been developed, has been incurred costs, and is ready to be marketed as soon as a price set, (3) limit in finding opportunities for innovation, (4) lack of support for short-term decision. How can we overcome these limitations of $\mathrm{ABC} / \mathrm{ABM}$ ? This paper draws the framework of integration of $\mathrm{ABC} / \mathrm{ABM}$ with other management accounting methods as one way to overcome its limitation and innovation management accounting. In the cope of this paper, authors focus on one model in the framework that is the integration of $\mathrm{ABB}$ with $\mathrm{ABM}$.
\end{abstract}

Keywords: Integration, Activity-Based Management (ABM), Activity-Based Budgeting (ABB)

\section{Introduction}

$\mathrm{ABC} / \mathrm{ABM}$ has brought humongous advantages and profits for many organizations as visual evidences. However, with the rapid change of today's economic environment, advanced technology, and the requirements of the modern enterprise's management force companies produce and supply its products at the lower price than its competitors do. The same goods or the functions of goods are the same but how to supply it to customer with the lower price and meet the customer need, and raise customer value. To solve this question, managers need to focus on detailed cost information provided by costing system. They need to look the detailed cost information in the past, the present, and the future in order to control cost and look for opportunities to reduce costs. ABM provides reliable cost information that need for innovation of organization operation. Reliable product cost information is considered as a powerful tool in increasing a company's profitability and competitiveness.

In the prior literature, there were many researches related to single $\mathrm{ABC} / \mathrm{ABM}$ method. We can classify the prior researches into three perspectives. (1) The researches related $\mathrm{ABC} / \mathrm{ABM}$ has many advantages than traditional system. (2) The researches related to disadvantages of $\mathrm{ABC} / \mathrm{ABM}$. (3) The researches related to implementation of $\mathrm{ABC} / \mathrm{ABM}$. The prior authors researched related to single $\mathrm{ABC} / \mathrm{ABM}$ method such as Qayoumi, 1996 $6^{[22]}$; Hixon, M., $1995^{[12]}$; Cooper and Kaplan, 1991 ${ }^{[8]}$; Akyol et al, 2005 ${ }^{[2]}$; Lewis, 1992 $2^{[16]}$; Cohen et al, 2005 ${ }^{[7]}$; Nassar et $a l, 2011^{[21]}$; Innes et al, 2000 $0^{[14]}$; Baird, 2007 ${ }^{[3]}$; Chen et al, $1993^{[4]}$; Liu and Pan, 2007 ${ }^{[18]}$; Zhang and Isa, 2010 ${ }^{[27]}$; Chongruksut and Brooks, $1993^{[6]}$. A little written about the integration of $\mathrm{ABC}$ with other management accounting methods such as $\mathrm{ABC}$ with GPK, $\mathrm{ABC}$ with Target Costing, $\mathrm{ABC}$ with Economic Value Added (EVA), and $\mathrm{ABC}$ with Balanced scorecard (BSC) (e.g., Gunther Friedl et al., $2005^{[9]}$; Wilbur I. Smith et al., 2002 $2^{[26]}$; Kaplan, $1998^{[15]}$; 
Matthew and Miller, $1988^{[19]}$; Roztocki and Needy, 1999 ${ }^{[23]}$; Chiadamrong, 2003 ${ }^{[5]}$; Huynh et al, 2013 ${ }^{[24]}$; Mohamed et al., 2012 $2^{[20]}$; Lim, 2001 ${ }^{[17]}$; Turney, 2005 ${ }^{[25]}$ ). However, the past literature lacks to research on ABB with ABM. This paper contributes to the literature the management method of ABB integrating with ABM.

\section{The Framework of ABC/ABM Integration}

By researching of the advantages and limitation of $\mathrm{ABC} / \mathrm{ABM}$ and other management accounting methods, this paper finds the best ways to overcome the shortcoming of theoretical $\mathrm{ABC} / \mathrm{ABM}$. This research draws the framework of $\mathrm{ABC}$ with standard costing, $\mathrm{ABC}$ with Target costing, $\mathrm{ABC}$ with Economic Value Added (EVA), ABC with $\mathrm{BSC}$, and $\mathrm{ABC}$ with traditional budgeting, and $\mathrm{ABB}$ with $\mathrm{ABM}$ as figure below.

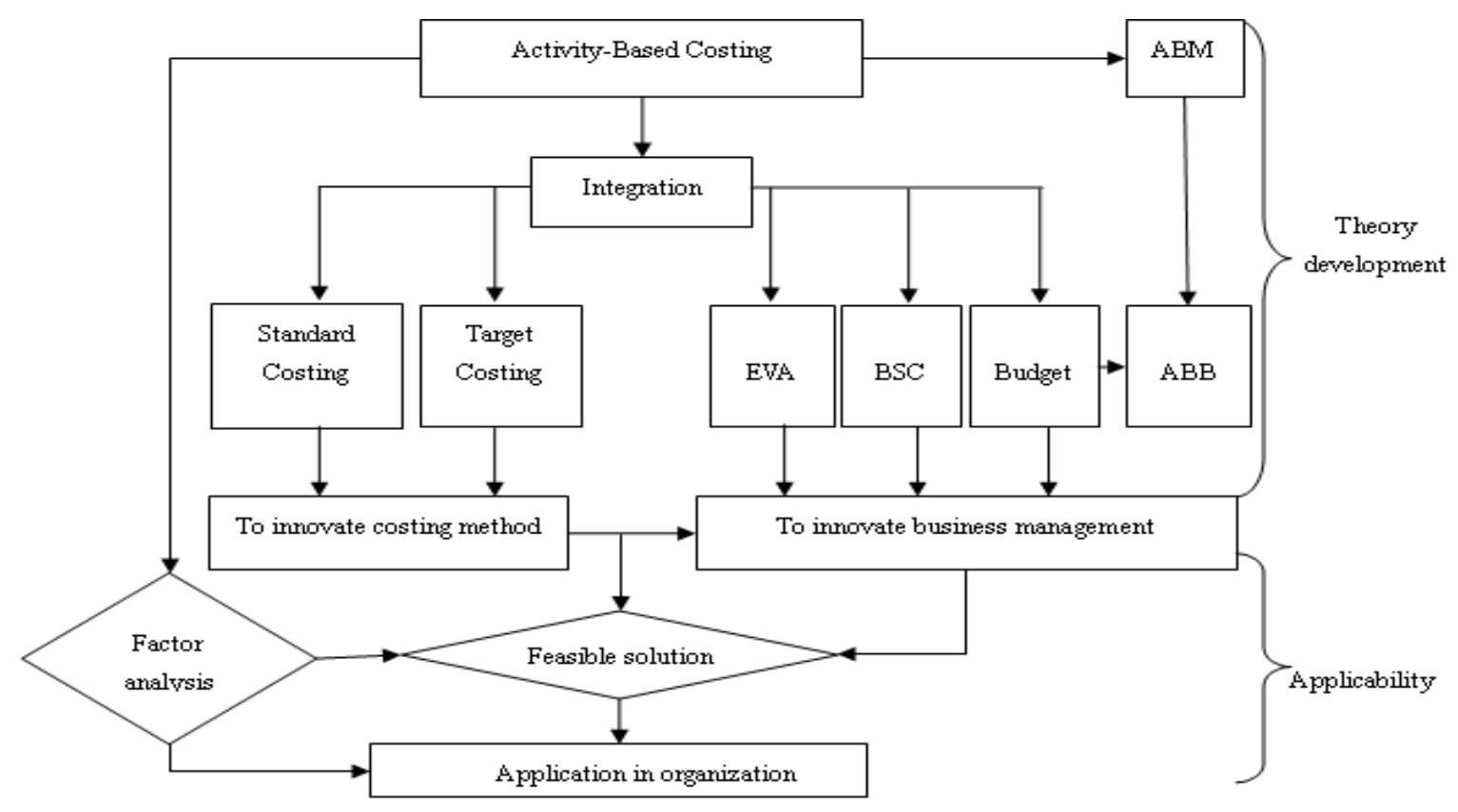

Source: own

Figure 1. ABC integration with other management accounting methods

By integrating $\mathrm{ABC}$ with other management accounting methods, this research explores advantages of $\mathrm{ABC}$, overcome its disadvantages and innovation a modern costing system based on $\mathrm{ABC} / \mathrm{ABM}$ models. The above framework of integrating $\mathrm{ABC} / \mathrm{ABM}$ with other management accounting methods supports guidance how to apply and expand them in the companies. In this paper, the methodology used is a type of theoretical mining and logical reasoning to explore the limitations of $\mathrm{ABB}$ and $\mathrm{ABM}$, and then the components of $\mathrm{ABB}$ and $\mathrm{ABM}$ can be used to overcome the shortcomings of each other. Next section, we discuss the integration of $\mathrm{ABB}$ and $\mathrm{ABM}$.

\section{Overview of Activity-Based Management}

\subsection{Nature of Activity-Based Management}

$\mathrm{ABM}$ is a system-wide, integrated approach that focuses management's attention on activities with the objectives of improving customer value and the profit archived by providing this value. $\mathrm{ABC}$ is the major source of information for activity-based management. Thus, the activity-based management model has two dimensions: a cost dimension and a process dimension.

The cost dimension provides cost information about resources, activities, and cost objects of interests such as products, customers, suppliers, and distribution channels. The objective of cost dimension is improving the accuracy of cost assignments. As the model (figure 2) suggests, the cost of resources is traced to activities, and the cost of activities is assigned to cost objects. This activity-based costing dimension is useful for product costing, strategic cost management, and tactical analysis. The second dimension, the process dimension, provides information about what activities are performed, why they are performed, and how well they are performed. This dimension's objective is cost reduction. This dimension also provides the ability to engage in and measure continuous improvement (Hansen and Mowen, 2003) ${ }^{[10]}$. $\mathrm{ABC}$ system is used to improve the operations of an organization in ABM. Costs are incurred in organization because of activities. A key feature of activity-based costing 
systems is that they measure and track the costs of significant activities over time. In addition, using the activity cost information collected in an ABC system, ABM involves the collection of financial or operational performance information about significant activities in the enterprise. The motivation for this process is twofold. First, the costing system attempts to assign the costs of significant activities to the products that cause those costs to be incurred. Second, by identifying the cost of activities, managers can attempt the reduction or elimination of unnecessary costs. $\mathrm{ABC}$ and $\mathrm{ABM}$ tend to strike a familiar chord with a variety of managers and employees throughout an enterprise. Activities are expressed in terms of events that are familiar to such diverse people as sale personnel, engineers, purchasing managers, inspectors, material handlers, production employees and shipping personnel (Hilton, 2002) ${ }^{[11]}$. In today's business environment, ABM is a useful cost management system. One of the most useful applications of ABM is distinguishing between value-added costs and non-value-added costs. Another ABC related technique that has gained popularity is benchmarking, the continuous process of comparing products, services, and

activities to the best industry standards. ABC system also focus on activities, its results are a very useful tool in cost management systems. ABM is using the output of an ABC system to aid strategic decision making and to improve operational control of an organization in order to achieve the aims: to improve the value received by customers and profits by identifying opportunities for improvements in strategy and operations. According to Kaplan (2008) ${ }^{[1]}$ $\mathrm{ABM}$ refers to the actions managers take, on the basic of an $\mathrm{ABC}$ study, to improve the efficiency of the activities and the profitability of products. Other ABM actions aim at improving processes, particularly the processes performing batch and product-sustaining activities. Another ABM action for transforming loss products into profitable ones is to impose a minimum other size to eliminate short, unprofitable production runs. The $\mathrm{ABC}$ system has provided managers with many insights that they can exploit to transform their currently unprofitable operations into profitable growth. Thus, to establish and apply ABM system to improve product quality, reduce costs in order to improve quality of life, eliminate poverty, and create wealth for social. It is the mission of the enterprise.

Cost Dimension

Resource Costs

to activity cost pools

associated with significant

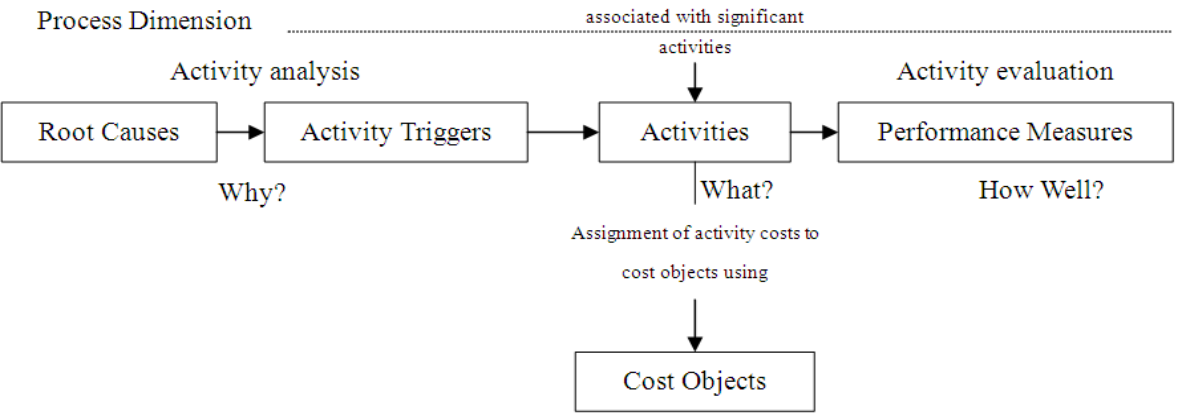

Source: Hilton (2002)

Figure 2. Two dimensions of Activity-based Management

\subsection{Benefits of $A B C$ and $A B M$}

$\mathrm{ABC} / \mathrm{ABM}$ systems bring many advantages for many companies applied them. They were focused by many several researchers as Kaplan et al (1998) ${ }^{[15]}$, Atkinson et al $(2008)^{[1]}$, Hansen and Mowen (2003) ${ }^{[10]}$, Horngren et al $(2007)^{[13]}$. As we known, traditional costing system is inexpensive to operate and simply to apply than $\mathrm{ABC}$, but it leads to large distortions in reporting the cost of activities, processes, products, services, and customers. Based on its information, managers may make serious mistakes in decision-making. An ABM system is more detailed and more accurate than a functional-based cost management system, has created a demand for strategic-based cost management. Horngren et al (2007) ${ }^{[13]}$ presented that although $\mathrm{ABC}$ systems are rather complex and costly to implement, more and more organizations in both manufacturing and nonmanufacturing industries are adopting $\mathrm{ABC}$ systems for variety of reasons:

1. Fierce competitive pressure has resulted in shrinking profit margin. Companies may know their overall margin, but they often do not have confidence in the accuracy of the margins for individual products or services. Some are winners and some are losers - but which ones? Accurate costs are essential for answering this question.

2. Greater diversity in type of products and services as well as customer classes results in greater business operating complexity. Therefore, the consumption of a company's shared resources also varies substantially across products and customers.

3. New production techniques have increased the proportion of indirect costs. That is, indirect cots are far more important in today's world-class manufacturing environment than they have been in the past. In many 
industries, automated equipment is replacing direct labor. Indirect costs are sometimes more than $50 \%$ of total cost.

4. The rapid pace of technological change has shortened product life cycles. Hence, companies do not have time to make price or cost adjustments once they discover costing errors.

5. The costs associated with bad decisions that result from inaccurate cost determinations are substantial.

6. Computer technology has reduced the costs of developing and operating the $\mathrm{ABC}$ systems.

In addition to helping managers understand manufacturing costs, $\mathrm{ABC}$ also enables managers to analyze customer profitability, redesign products, product substitution, improve processes and operations strategy, technology investment, and eliminate waste products.

\section{Overview of Activity-Based Budgeting}

\subsection{The Role of Budgeting In Planning and Control}

Budgeting plays a crucial role in planning and control. Plans identify objectives and the actions needed to achieve them. Budgets are the quantitative expressions of these plans, stated in either physical or financial terms or both. When used for planning a budget is a method for translating the goals and strategies of an organization into operational terms. Budgets can also be used in control. Control is the process of setting standards, receiving feedback on actual performance, and taking corrective action whenever actual performance deviates significantly from planned performance. Thus, budgets can be used to compare actual outcomes with planned outcomes, and they can steer operations back on course, if necessary. The illustration of the relationship of budgets to planning, operating, and control showed as below. Budgets evolve from the long-run objectives of the firm; they form the basis for operations. Actual results are compared with budgeted amounts through control. This comparison provides feedbacks both for operations and for future budgets (Hansen and Mowen, 2003) ${ }^{[10]}$.

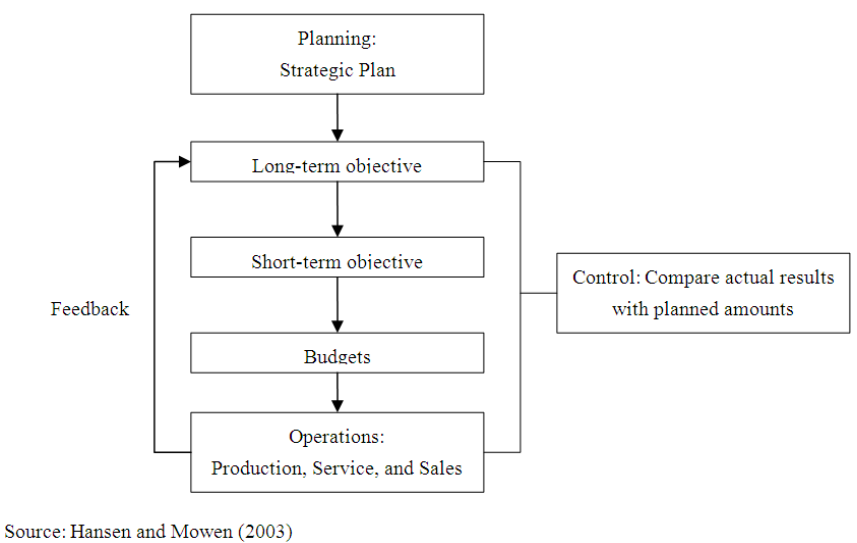

Figure 3. Purposes of Budgeting
Budgets are usually prepared for areas within an organization (departments, plants, divisions, and so on) and for activities (sales, production, research, and so on). This system of budgets serves as the comprehensive financial plan for the organization as a whole and gives an organization several advantages: (1) it forces managers to plan; (2) it provides resource information that can be used to improve decision making; (3) it aids in the use of resources and employees by setting a benchmark that can be used for the subsequent evaluation of performance; (4) it improves communication and coordination. Budgeting forces management to plan for the future: to develop an overall direction for the organization, foresee problems, and develop future policies. When managers spend time planning, they grow to understand the capabilities of their businesses and where the resources of the business should be used. Budgets enable managers to make better decisions. They help managers foresee potential differences especially in shortfalls. By analyzing differences to find the cause, help managers improve organization activities in order to achieve the plans. Budgets set standards that can control the use of a company's resources and control motivate employees. Fundamental to the overall success of a budgetary system, control ensures that steps are being taken to achieve the objectives outlined in an organization's master plan. They also serve to communicate the plans of organization to each employee and to coordinate their efforts. Accordingly, all employees can be aware of their role in achieving those objectives. This is why explicitly linking the budget to the long-run plans of organization is so important. The budget is not series of vague, rosy scenarios, but a set of specific plans to achieve those objectives. Budgets encourage coordination because various areas and activities of the organization must all work together to achieve the stated objectives. The role of communication and coordination become more important as an organization increases in size (Hansen and Mowen, 2003) ${ }^{[10]}$.

\subsection{Activity-Based Budgeting}

Horngren et al (2007) ${ }^{[13]}$ presented most business organizations use budget to focus attention on company operation and finances, not just limit to spending. Budgets highlight potential problems and advantages early, allowing managers to take steps to avoid these problems or use the advantages wisely. A budget is a tool that helps managers both their planning and control functions. Budgets help managers plan for the future. However, managers also use them to evaluate what happened in the past. Study after study has shown that the budget to be one of the most widely used and highest rate cost-management tools for cost reduction and control. Advocates of budgeting go so far as to claim that the process of budgeting forces a manager to become a better administrator and puts planning in the forefront of the manager's mind. Actually, many seemingly healthy businesses have died because managers failed to draw up, monitor, and adjust budgets to changing conditions. The major benefits of budgeting can summary 
as follow: (1) budgeting compels managers to think ahead by formalizing their responsibilities for planning, (2) budgeting provides expectations that are the best framework for judging subsequent performance, and (3) budgeting aids managers in coordinating their efforts, so that the plan of an organization's submits meet the objective of the organization as a whole (Horngren et al, $2007)^{[13]}$. However, in today's business environment, a number of organizations and people have been very critical of the traditional budgeting process. These critics argue that the traditional budgeting process does following: (1) reflect a top-down approach to organizing that is inconsistent with the need to be flexible and adapt to changing organization circumstance, (2) focuses on controls rather than focusing on helping the organization achieve its strategic objectives, and (3) causes resource allocations to be driven by politics rather than strategy. That is, political power in the organization drives resource allocations rather than the strategic needs that drive traditional budgeting (Kaplan $1998)^{[15]}$

A recent approach to budget is activity-based budgeting that is based on ABC. Activity-based budgeting uses knowledge about the relationships between the quantity of production units and the activities required to produce those units to develop detailed estimate of activity requirements underlying the proposed production plan. The two main benefits of $\mathrm{ABB}$ are: (1) it identifies situations when production plan require new capacity - both physical capacity and capacity in people resources - to deliver much of support and service activities in organizations. (2) It provides a more accurate way to project future costs (Kaplan $(2008)^{[15]}$. Hansen and Mowen $(2003)^{[10]}$ presented that the ABB begins with output and then determines the resources necessary to create that output. Ideally, the organization translates its vision into a strategy with definable objectives in order to create value. Ways of creating value include growing market share, improving sales rates, reducing expenses, increasing profit margins, increasing productivity, and reducing the cost of capital.

We can look at a budget from three perspectives: a traditional functional-based approach, a flexible budgeting approach, and an activity-based approach. Traditional budgeting relies on the use of functional-based line items, such as salaries, supplies, depreciation on equipment, and so on. The flexible budget uses knowledge of cost behavior to split the functional-based line items into fixed and variable components. The ABB works backward from activities and their drivers to the underlying costs.

Traditional budgeting focuses on the result, not the process or root cause. $\mathrm{ABB}$, by focusing on the process, give managers guidance in the way to achieve the desired results. When activity-based budgeting is used, the root causes can be identified, and this knowledge can be used to effect process and cost efficiencies (Hansen and Mowen, $2003)^{[10]}$. A comparison of $\mathrm{ABC}$ and $\mathrm{ABB}$ is shown in figure 4 as follow:

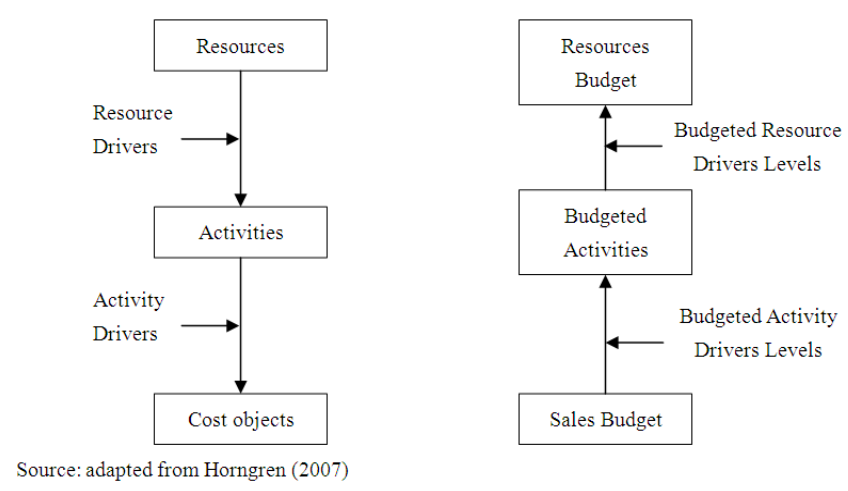

Figure 4. $A B C$ and $A B B$ compared

$\mathrm{ABB}$ process is a reverse process of $\mathrm{ABC}$ approach. The above figure highlights the main concepts and differences between $\mathrm{ABC}$ allocation of resource costs to activities and products, and $\mathrm{ABB}$ does. $\mathrm{ABB}$ begins with the forecasted demand for goods (sales budget). It focuses on estimating the demand for each activity's output as measure by its cost driver. Then using the rate at which activities consume resources to estimate or budget the resource needed. ABB emphasis on activities and their consumption of resources, some managers believe that it is more useful for controlling waste and improving efficiency. According to Hansen and Mowen (2007) ${ }^{[10]}$, in order to build an ABB four steps are needed.

Step 1: The output of the department must be determined;

Step 2: The activities needed to deliver the output, along with their related drivers, must be identified;

Step 3: The demand for each activity must be estimated;

Step 4: The cost of resources required to produce the relevant activities must be determined.

It is critically important to see that $A B B$ is based on expected output. Traditional budget often plans forward from last year's experience, while ABB plans backward from next year's output. The differences between the two approaches are more than semantic. In addition, the ABB approach, using resources and activities to create output, gives the managers much more information as well as ability to consider eliminating non-value-added activities. (Hansen and Mowen, 2003) $^{[10]}$.

\section{Activity-Based Budgeting and Activity-Based Management Integration}

Controlling and improving efficiency are the primary objectives of a budget. As we analyzing above, ABB have many advantages compare with traditional budgeting. However, ABB just emphasizes the planning and control purpose of cost management. $\mathrm{ABB}$ lacks of in how to manage organization operating to achieve what ABB drawn. $\mathrm{ABB}$ drawn the target and encourages managers to works toward achieving the organization's goals. How can managers run the actual organization's operating to reach 
ABB line? The mangers need ABM help to manage actual judgments in order to get the best way for goals achieving. When an organization implements $\mathrm{ABC}$ system for costing its products, it needs to constructs the management system and budgeting based on activity-based. It is not logical if an organization using $\mathrm{ABC}$ calculates product costs but it is set a management systems and budgeting based on traditional methods. However, how can $\mathrm{ABB}$ and $\mathrm{ABM}$ support each other? How can we integrate ABB and ABM? This paper draws the framework to present the integration of $\mathrm{ABB}$ and
ABM.

$\mathrm{ABB}$ and $\mathrm{ABM}$ well consider all the entire value chain; it serves as an effective model for decision-making. Both methods have function to help managers achieve the organization's goals. They also help managers is to create the value for an organization. Both $\mathrm{ABB}$ and $\mathrm{ABM}$ are the modern methods and used for achieving these purposes. Integration of $\mathrm{ABB}$ and $\mathrm{ABM}$ is used toward to increase value creating for organizations.

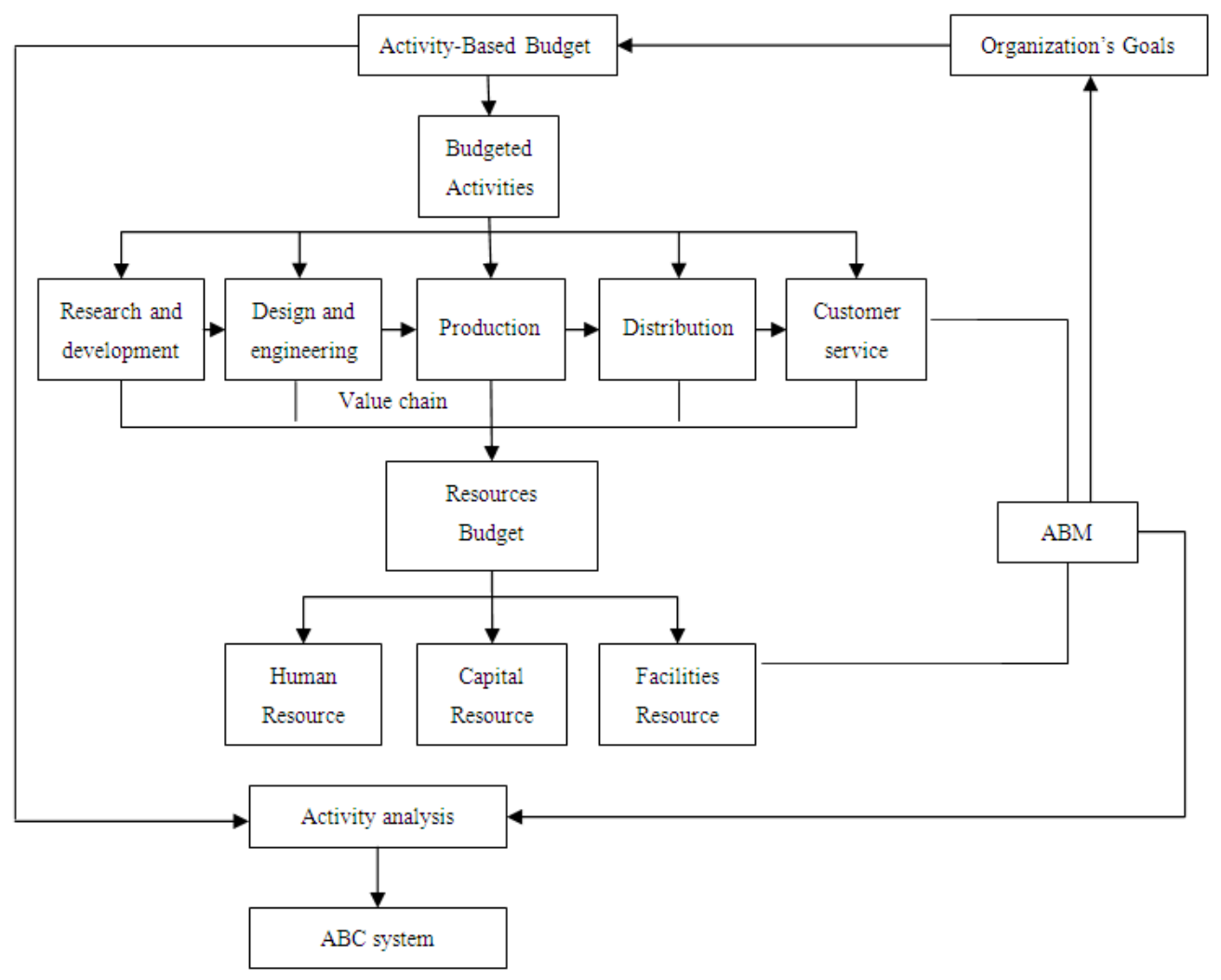

Source: own

Figure 5. $A B B$ and ABM integration

The organization uses ABB to evaluate its efficiency and effectiveness. Efficiency is achieved when the business process is performed in the best possible way, with little or no waste. The ABB provides an assessment of the efficiency of a manager. This is because we can compare the actual results with the results-based budgeting activity. Effectiveness means that a manager achieves or exceeds the goals described. Thus, efficiency examines how well the work is done, and effectiveness examines whether or not the right work is being accomplished. These perspectives need the function of ABM.

\section{Conclusions}

In this paper, an attempt has been made to present the background of $\mathrm{ABC} / \mathrm{ABM}$ and other management accounting methods integration in order to overcome shortcomings of $\mathrm{ABC} / \mathrm{ABM}$ and foster their advantages to support each other for achieving the organization' goals in the best results. The integration of $\mathrm{ABB}$ and $\mathrm{ABM}$ focuses on both actual results and results-based budgeting. It gives managers a comprehensive view of the organization's results. Under $\mathrm{ABB}$ integrating with $\mathrm{ABM}$, top managers can accurately assess the responsibility of all levels of management.

Integration of $\mathrm{ABB}$ and $\mathrm{ABM}$ provide needed information for management to make right decisions is very important in today's global competitive environment. It helps managers not only to solve the matters realize value-added activities and non-value-activities but also to know the activities fall significantly outside results-based budgeting. Managers are alerted that there must be problems requiring attention.

The only shortcoming of $\mathrm{ABB}$ and $\mathrm{ABM}$ integration is that lacks to discuss target cost. Further research will be done to join $\mathrm{ABB}$ and $\mathrm{ABM}$ integration method with target costing. This gives a perfect method for managers to run control and make accurate decision in their organizations. 


\section{Acknowledgements}

We would like to thank Professor Guangming Gong leader of Business School of Hunan University and CPA, MBA Nguyen Tan Quang suggested idea for this paper. Finally, we thank to all authors that our paper cited.

\section{References}

[1] Atkinson, A.A., Kaplan, R.S., Matsumura, E.M. and Young, 2008. Management Accounting, Peking: Tsinghua University Press

[2] Akyol, D.E., Tuncel, G. and Bayhan, G.M., 2005. A Comparative Analysis of Activity-Based Costing and Traditional Costing. World Academy of Science, Engineering and Technology, 3, 44-47

[3] Baird, K., 2007. Adoption of activity management practices in public sector organizations. Accounting and Finance, 47, 551-569

[4] Chen, G.M., Firth, M. and Park, K., 1993. The implementation and benefits of activity-based costing: a Hong Kong study. Asian Review of Accounting, 9(2), 23-37

[5] Chiadamrong., 2003. Integrating ABC and EVA to evaluate investment decisions, ASEAN Journal Science and Technology Development (AJSTD), 20(1), 87-95

[6] Chongruksut,. W. and Brooks, A., 1993. The adoption and implementation of Activity-Based Costing in Thailand. Asian Review of Accounting, 13(2), 1-17

[7] Cohen, S., Venieris, G. and Kaimenaki, E., 2005. ABC: adopters, supporters, deniers and unawares. Managerial Auditing Journal, 20(9), 981-1000.

[8] Cooper, R. and Kaplan, R.S., 1991. Profit priorities from activity-based costing. Harvard Business Review, May-June, 130-135.

[9] Gunther Friedl, Hans-Ulrich Kupper, Burkhard Pedell., 2005. Relevance Added: Combining $\mathrm{ABC}$ with German Cost Accounting. Strategic Finance, 6, 56-61

[10] Hansen, D.R. and Mowen, M.M., 2003. Cost management: Accounting and Control. Peking, Peking University Press.

[11] Hilton, Ronald W., 2002. Managerial accounting: creating value in a dynamic business environment (5th Ed), China Machine Press.

[12] Hixon, M., 1995. Activity-based management: its purpose and benefit. Management Accounting, June.

[13] Horngren, C.T., Sundem, G.L. and Stratton, W.O., 2007. Introduction to management accounting. Peking, Peking University Press.

[14] Innes, J. and Mitchell, F., 2000. Activity-Based Costing in The U.K.'S Largest Companies: A Comparison of 1994 And
1999 Survey Results. Management Accounting Research, 11, 349-362

[15] Kaplan, R.S. and Atkinson, A.A., 1998. Advanced Management Accounting. Prentice Hall International, Inc.

[16] Lewis, L.D., 1992. Activity-Based Costing: A tool for management. Central Business Review, 11(2), 28-30.

[17] Lim. A., 2001. The importance of activity based costing / management to the balanced scorecard, Available at: www.apmss.com.sg/pdf/importanceof-abcinbsc.pdf.

[18] Liu, L.Y.J. and Pan, F., 2007. The implementation of Activity-Based Costing in China: An innovation action research approach. The British Accounting Review, 39, 249-264

[19] Matthew, J, Miller, T., 1998. A framework for integrating activity-based costing and balanced scorecard into the logistics strategy development and monitoring process. Journal of Business Logistics, 19, 131-138

[20] Mohamed M. El Gibaly and Ahmed Abdelnaby Ahmed Diab., 2012. A model to integrate of the ABC and the BSC in the Egyptian companies: Aligning strategic efficiency and performance improvement (Field study). Journal of American Science, 8(6), 543-554

[21] Nassar, M., Al-Khadash, H.A. and Sangster, A., 2011. The diffusion of Activity-Based Costing in Jordanian industrial companies. Qualitative Research in Accounting \& Management, 8(2), 180-200.

[22] Qayoumi, M.H., 1996. Using activity-based management as a vehicle for managing change. Facilities Manager, 12(1), 28-32

[23] Roztocki, N., \& Needy, K. L., 1999. Integrating Activity-Based Costing and Economic Value Added in Manufacturing. Engineering Management Journal, 11(2), $17-22$.

[24] Tandung Huynh, Guangming Gong, Anhtuan Nguyen., 2013. Integrating activity-based costing with economic value added. Journal of Investment and Management, 2(3), 34-40

[25] Turney, P.B., 2005. Linking $\mathrm{ABC} / \mathrm{M}$ and the balanced scorecard. Cost Technology Inc. Available at: http://www.dc349.4shared.com/doc/uoRZLivj/preview.html

[26] Wilbur I. Smith, Gabrielle Lewis, Tremika Churchwell, and Colin Benjamin., 2002. Integrating Activity-Based Costing, Target Costing, And Value Engineering For Supply Chain Improvement, $\quad 447-452$ http://ieeexplore.ieee.org/xpls/abs_all.jsp?arnumber=104947 9\&tag=1.html

[27] Zhang, Y.F. and Isa, C.R., 2010. Behavioral and organizational variables affecting the success of $\mathrm{ABC}$ success in China. African Journal of Business Management, 4(11), 2302-2308. 